\title{
Altered expression of ezrin, E-Cadherin and $\beta$-Catenin in cervical neoplasia
}

\author{
E. AUVINEN ${ }^{1,2, *}$, O. CARPEN ${ }^{3}$, T. KORPELA ${ }^{3}$, M. RONTY ${ }^{4}$, A. VAHERI ${ }^{1}$, J. TARKKANEN ${ }^{4}$
}

${ }^{1}$ Department of Virology, Haartman Institute, University of Helsinki, POB 21, 00014 University of Helsinki, Finland; ${ }^{2}$ Department of Virology and Immunology, Helsinki University Central Hospital Laboratory, POB 400, 00029 HUS Helsinki, Finland; ${ }^{3}$ Department of Pathology, University of Turku and Turku University Central Hospital, Kiinamyllynkatu 12, 20520 Turku, Finland; ${ }^{4}$ Department of Pathology, Helsinki University Central Hospital Laboratory, POB 400, 00029 HUS Helsinki, Finland

*Correspondence: eeva.auvinen@helsinki.fi

Received May 11, 2012 / Accepted July 3, 2012

\begin{abstract}
High-grade cervical squamous intraepithelial lesions (CIN) as well as squamous cell carcinoma and adenocarcinoma of the cervix are associated with persistent high-risk human papillomavirus (HPV) infection. A number of cellular events play a role in HPV pathogenesis and in the development of cervical lesions, including alterations in cell adhesion and motility. The crucial plasma membrane - cytoskeleton linker protein ezrin of the Ezrin-Radixin-Moesin (ERM) protein family is involved in the regulation of cell morphology, cell adhesion and invasion. Based on our previous work on ERM proteins we sought out to study the expression of ezrin in cervical premalignant lesions. We also studied the expression of E-cadherin and $\beta$-catenin, which play an important role in epithelial cell adhesion. We observed intensifying expression of ezrin along with progressing grade of neoplasia. Ezrin staining was found to colocalize with p16 staining in high-risk HPV associated lesions. Expression of E-cadherin and $\beta$-catenin was found to be altered along with the severity of the lesion, similar to ezrin. Enhanced expression of ezrin in cervical HPV associated lesions suggests a role in the development of cervical neoplasia and cancer. Further clinical evaluation should reveal the feasibility of ezrin as a biomarker for the progression of cervical lesions.
\end{abstract}

Key words: CIN, ezrin; HPV, papillomavirus

Human papillomavirus (HPV) infections of the female genital tract are common, but most infections clear spontaneously and only a small percentage will develop into high-grade epithelial lesion or cancer [1]. Extensive studies have been undertaken in order to understand the process of cervical carcinogenesis and to recognize cellular factors promoting tumorigenesis. Most importantly, good biomarkers to recognize those HPV infections which will eventually develop into severe cervical disease are lacking. The tumor suppressor p16INK4a is a cyclin-dependent kinase inhibitor, which regulates cell cycle progression by mediating $\mathrm{pRb}$ phosphorylation or dephosphorylation by CDK4 and CDK6 [2]. Upregulation of p16INK specifically due to high-risk (hr) HPV E7 oncogene expression has been used as a surrogate marker for hrHPVassociated cervical dysplasia in paraffin-embedded tissue [3]. Additional cellular markers, preferrably of prognostic value, would greatly contribute to differential diagnostics, and to the management of patients with borderline cervical cytology, where follow-up and treatment may be challenging.
Ezrin, cloned originally independently by us and by another group, is a member of the ERM protein family consisting of plasma membrane - cytoskeleton organizers Ezrin, Radixin, and Moesin [4-6]. Increased ezrin expression is associated with the proliferative phenotype in vitro [7]. Increased expression of ezrin has been reported in epithelial and other tumors and in tumor-derived cell lines [8-10], and a direct role for ezrin in invasion and metastasis has been established in our work and in the work of others [11-13]. We have previously studied the role of ezrin in epithelial cells and found that its localization at membrane junctions is essential for the regulation of Racl, a member of the Rho family proteins important in epithelial cell morphogenesis [14]. There are little data about the interactions of HPV and ezrin. In our recent study on the HPV 16 E5 oncogene functions, however, we found slightly reduced expression of ezrin in three-dimensional collagen raft cultures of $\mathrm{HaCaT}$ epithelial cells expressing the HPV 16 E5 oncogene, although increased membrane staining was seen towards the epithelial surface in a cervical 
intraepithelial neoplasia (CIN) tissue [15]. Further, ezrin has been found essential for the tumorigenic Six-1 homeoprotein mediated metastasis $[12,16]$. Upregulation of Six-1 has been reported in an in vitro model for cervical tumorigenesis and confirmed in a microarray screen from cervical keratinocytes immortalized with HPV 16 [17]. The exact roles of ezrin or Six-1 in cervical carcinogenesis have not, however, been properly investigated.

E-cadherin is a crucial molecule in a number of biological functions such as cell-cell adhesion, epithelial morphogenesis and differentiation [18], which are affected upon the development of CIN lesions and cervical cancer. Altered expression and intracellular localization of E-cadherin and catenins are associated with impairment of differentiation of cervical epithelium in dysplasia [19]. Decreased expression of E-cadherin at the plasma membrane as well as relocalization of important catenins from the membrane to the cytoplasm has been observed in cells immortalized and transformed by HPV [20]. Interestingly, in our previous work we found modest upregulation of E-cadherin and $\beta$-catenin in monolayer cells and in three-dimensional cultures expressing the E5 oncogene of HPV 16, as well as in CIN [15].

Encouraged by our previous findings we studied the expression of important cell adhesion and cell motility associated proteins in cervical disease. We show altered expression of ezrin and Six-1, together with E-cadherin and $\beta$-catenin, in a set of tissue samples representing different stages of HPV associated epithelial dysplasia. The results suggest that ezrin has a role in cervical neoplastic disease, and its feasibility as a biomarker is worthy of clinical validation.

\section{Patients and methods}

Patients and samples. Histological samples used in this study were obtained from women referred to colposcopy on the basis of repeated abnormal Papanicolaou (pap) smear. Colposcopy was performed at the Women's Hospital of the Helsinki University Central Hospital. In colposcopy a punch biopsy or large loop excision of the transformation zone of the cervix (LLETZ) was performed. Tissue material from either procedure was fixed in $10 \%$ buffered formaldehyde, prepared in routine manner in the pathology laboratory, and stained with hematoxylin-eosin. Altogether, 26 cervical intraepithelial neoplasia (CIN) grade 1 samples, 12 CIN2 samples, 3 CIN3 samples and 4 adenocarcinoma in situ (AIS) samples were collected. Normal squamous epithelium and normal endocervical glands were also represented for comparison. Clinical characteristics of the patients and samples are presented in Table 1.

Ethical issues: The use of archival human samples in this study was approved by the Coordinating Ethical Committee of the Helsinki University Central Hospital (69/E0/07).

High-risk HPV DNA Testing. High-risk HPV DNA testing was performed using the Hybrid Capture 2 test (HC2; Qiagen, Gaithersburg, MD) from a cytological sample, when available, collected at colposcopy. The probe mixture in the HC2 test contained hrHPV types $16,18,31,33,35,39,45,51,52,56$, 58,59 , and 68 . The HC2 test gives a hrHPV positive/negative result without genotyping of HPV.

Immunohistochemical Staining. Five- $\mu \mathrm{m}$ paraffin sections were prepared for automated immunohistochemical staining with LabVision Autostainer (Lab Vision Inc., Fremont, CA), Ventana Benchmark, or Ventana Discovery (Ventana Medical Systems, Tucson, AZ) instruments. After deparaffinization, antigen retrieval was performed using citrate-containing buffer (CC1 buffer, Ventana Medical Systems). Mouse monoclonal antibodies to ezrin clone 3C12 (our own clone [21]), p16INK4a clone E6H4 (DakoCytomation, Glostrup, Denmark), E-cadherin clone 36 (BD Transduction Laboratories, Franklin Lakes, NJ), and $\beta$-catenin clone 14 (BD Transduction Laboratories), as well as a rabbit antibody to Six-1 (Atlas Antibodies, Stockholm, Sweden) were used. The antibody signal was amplified and detected using biotinylated secondary antibody followed by streptavidin-conjugated horseradish peroxidase and diaminobenzidine (DAB) or aminoethylcarbazole (AEC) substrate.

\section{Results}

Samples from CIN1-3 and AIS lesions, together with normal tissue, were studied for the expression of ezrin, Ecadherin, $\beta$-catenin and p16INK by immunohistochemical staining, and the hrHPV status of the patients was determined (Table 1.). Among HPV-tested CIN1 cases, not all samples were hrHPV positive as expected: cytological samples from $12 / 25$ patients ( $48 \%$ ) were hrHPV positive as determined by the hrHC2 test. All CIN2 and CIN3 cases were positive for hrHPV DNA. No samples for hrHPV testing were available from AIS patients (Table 1.).

The immunohistochemical staining results for p16, ezrin, E-cadherin and $\beta$-catenin are shown in Figure 1. p16INK was not expressed in normal cervical squamous epithelium or in endocervical glands of normal columnar epithelium. In hrHPV-associated dysplastic lesions (CIN1-3), cytoplasmic as well as nuclear staining for p16INK was seen, correlating with the severity of the lesion. In CIN1, the lower part of the dysplastic epithelium stained strongly positive for p16INK, whereas the superficial koilocytotic areas of high-risk HPV negative CIN1 lesions remained faintly stained. The junction

Table 1. Clinical characteristics of the 45 samples studied. hrHPV, highrisk human papillomavirus; CIN1-3, cervical epithelial neoplasia grade 1-3; AIS, adenocarcinoma in situ; ND, not done.

\begin{tabular}{lcc}
\hline Histology & N:o & hrHPV positive \\
\hline CIN1 & 26 & $12 / 25^{\star}(48 \%)$ \\
CIN2 & 12 & $12(100 \%)$ \\
CIN3 & 3 & $3(100 \%)$ \\
AIS & 4 & ND \\
\hline
\end{tabular}

*A cytological sample for hrHPV testing was unavailable from one CIN1 patient. 


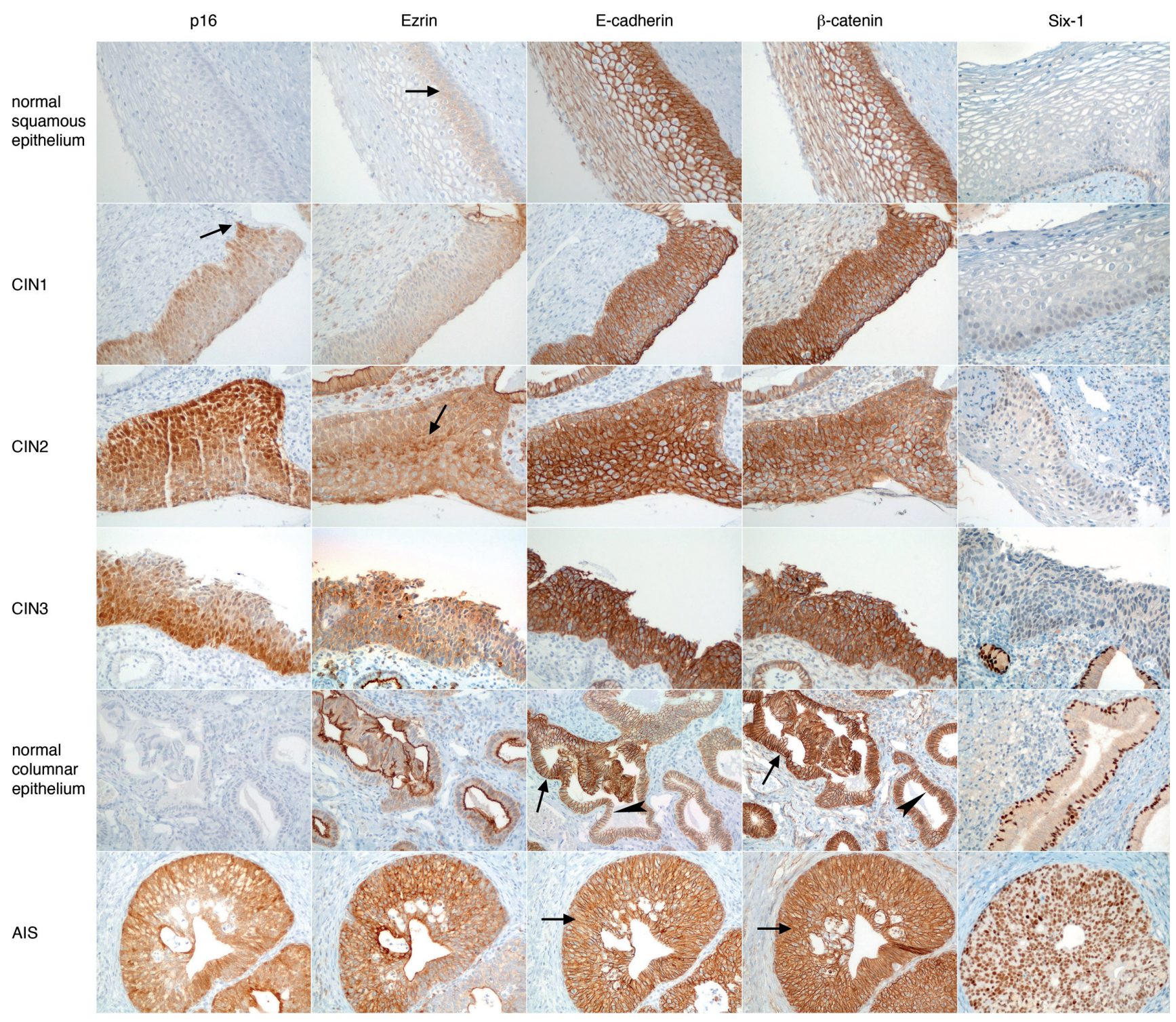

Figure 1. Immunohistochemical staining in cervical tissue. Shown are normal squamous epithelium, cervical intraepithelial neoplasia (CIN) 1-3, normal columnar epithelium with endocervical glands, and adenocarcinoma in situ (AIS) stained for p16, ezrin, E-cadherin, $\beta$-catenin, and Six-1. Arrows: p16 at the junction between squamous and columnar epithelium in CIN1; basal and suprabasal staining for ezrin in normal squamous epithelium; zone of strong ezrin staining in the middle layers of the epithelium in CIN2; basolateral E-cadherin and $\beta$-catenin staining in normal columnar epithelium; cytoplasmic E-cadherin and $\beta$-catenin staining in AIS. Arrowheads: lack of staining for E-cadherin and $\beta$-catenin at the apical side of columnar epithelial cells. All images were taken in a 20x magnification.

between layered squamous epithelium (p16 positive) and simple columnar epithelium (p16 negative), representing a frequent site for HPV infection, is shown (arrow). In AIS, staining for p16INK was strongly positive.

In normal stratified squamous epithelium of the cervix, membrane and cytoplasmic ezrin staining was seen in basal and parabasal cell layers (arrow), whereas mature superficial cells were largely negative (Figure 1). In CIN1, increased membrane and cytoplasmic staining throughout the squamous epithelium was seen in both hrHPV positive and hrHPV negative cases. In CIN2, a zone of strong ezrin staining was typically seen in the cell middle layers of the epithelium (arrow). Altogether, in CIN2 and CIN3 a tendency towards stronger staining both at the membrane and in the cytoplasm throughout the epithelium was seen, although grading of dysplasia on the basis of ezrin staining intensity alone proved difficult. In normal cervical glands, intense membrane-associated staining for ezrin was seen in the apical surface of epithelial cells with faint cytoplasmic staining. Inflammatory cells were also positive. In adenocarcinoma in situ the inten- 
sity of ezrin immunoreactivity was increased as compared to normal cervical glands, and polarized distribution was lost. Although the same regions were stained for ezrin as for p16, the zonal intense staining seen for ezrin particularly in CIN2 was not seen for p16INK, and the intracellular distribution of the two proteins was different.

Normal squamous epithelium showed positive membrane staining at adherens junctions for E-cadherin in basal and parabasal cells but fainter staining at the epithelial surface (Figure 1). In both hrHPV positive and hrHPV negative CIN1, membrane staining reached the upper epithelial layers. An intense zonal membrane staining was seen in the middle cell layers of the epithelium (Figure 1). In CIN2-3 more intense membrane staining covered the whole epithelium and the zonal gradient of staining intensity, as seen for ezrin, was absent. Normal glands showed faint basolateral (arrow) but no apical membrane staining (arrowhead). In AIS there was strong membrane positivity together with faint cytoplasmic staining (arrow) for E-cadherin.

$\beta$-catenin in normal squamous epithelium showed strong granular staining in adherens junctions with little cytoplasmic signal (Figure 1). Strong staining did not reach the differentiating cells of the epithelial surface. In CIN1 lesions there was markedly strong membrane staining which continued as a somewhat fainter staining all the way to the epithelial surface. No difference in the staining pattern was seen between hrHPV positive and negative lesions. In CIN2-3 the membrane staining was equally strong from basal cells to the epithelial surface. In normal glands of columnar epithelium there was finely granular $\beta$-catenin staining at the membrane (arrow), but apical staining was absent (arrowhead). AIS had marked membrane staining and faint cytoplasmic staining throughout the epithelium (arrow).

Nuclear staining for Six-1, which stained roughly in the same regions of the epithelium as ezrin, was very weak in both normal and dysplastic cervical squamous epithelium. However, in normal columnar epithelium and in AIS strong nuclear staining was seen (Figure 1).

\section{Discussion}

In order to understand the role of ezrin in cervical pathogenesis and to establish putative novel marker proteins for cervical dysplasia we studied the expression of ezrin, E-cadherin and $\beta$-catenin in CIN1-3 and adenocarcinoma in situ lesions of the uterine cervix. In this work we found that the expression of the cytoskeletal organizer protein ezrin was increased along with the severity of HPV-associated CIN. Strong staining for ezrin with diffuse intracellular distribution was also seen in AIS, whereas the distribution in normal endocervical tissue was strongly polarized to the apical side of columnar epithelial cells. CIN is exclusively caused by HPV, but the increased expression of ezrin may be directly or indirectly dependent on the expression of HPV proteins. In our previous work we observed slightly reduced ezrin expression due to HPV 16 E5 [15] which is an oncogene facilitating the early events in the neoplastic development, suggesting that increased expression of ezrin would rather be a consequence of E6 and/or E7 oncogene expression.

The impact of ezrin in cervical carcinogenesis is not known, although evidence of a key role for ezrin in carcinogenesis and metastasis is accumulating [11-13, 22]. Ezrin has been recognized as an important contributor to tumor metastasis [11-12]. In the latter work, ezrin was found to be a key metastatic regulator of soft-tissue sarcomas, and the authors concluded that expression of ezrin associated strongly with aggressive malignancy [12]. In canine and pediatric osteosarcoma, high expression of ezrin was associated with early development of metastases and poor disease outcome $[9,11,23]$. We have previously shown that high ezrin expression in cutaneous and uveal melanoma associates with poor prognosis [24-25]. A correlation between ezrin expression and metastatic behavior and increased proliferation has also been demonstrated in ovarian and pancreatic adenocarcinoma cells [8, 26-27]. In a human embryonic esophageal cell line transformed with the HPV 18 E6 and E7 oncogenes, one of the fifteen upregulated genes during malignant transformation was ezrin, and ezrin expression correlated with the invasive phenotype [10]. Further, ezrin was shown to contribute to cervical cancer cell invasiveness through binding to $\mathrm{Na}+\mathrm{H}+$ exchanger NHE1 [28]. In that paper, ezrin was shown to colocalize with and physically bind to NHE1 in EGF-stimulated cervical cancer cells. Our present findings of altered ezrin expression in cervical neoplasia are in line with these earlier data and suggest a possible role for ezrin in the development of cervical disease.

The involvement of ezrin in Six-1-promoted metastasis has been reported [12]. Six-1 and ezrin were found to regulate metastasis in a microarray study of a rhabdomyosarcoma mouse model [12]. The interrelationship and the requirement for ezrin in Six-1 metastatic function has been established by Wan et al. [17], who showed direct activation of ezrin promoter by Six-1, and a requirement for ezrin in the prometastatic function of Six-1. Although we showed strong nuclear Six-1 staining in normal columnar epithelium and AIS, the staining was very weak in normal and dysplastic squamous epithelium. Six-1 stained the same regions of the epithelium as ezrin. However, no conclusion could be made of its altered expression in cervical disease.

We found E-cadherin expression in basal and suprabasal cells of normal epithelium, whereas in HPV-infected tissue the stronger basal cell expression was lost and instead punctuate E-cadherin staining in upper cell layers was seen. Staining for E-cadherin and ezrin was altered in a similar manner along with the severity of the lesion. Altered distribution of E-cadherin and $\beta$-catenin in cervical carcinoma has been reported before [29-31]. In most invasive cervical carcinomas those authors found E-cadherin and $\beta$-catenin expression mostly in the cytoplasm, while we show a strong membrane staining in CIN. Alterations in intercellular junctions and differences therein, even between morphologically similar cells, may be 
crucial in the development of cervical lesions [32-33]. Along with the malignant development, the E-cadherin/ $\beta$-catenin complex at the plasma membrane is claimed to be degraded and $\beta$-catenin is transported to the nucleus where it acts as a transcription factor in the Wnt signaling pathway and contributes to malignant development [18].

Downregulation of E-cadherin in HPV-infected skin has been reported [34]. Transfection of E-cadherin into a differentiationresistant subpopulation of HPV-transformed cells reverses the invasive phenotype [20]. Intriguingly, ezrin has been shown to regulate cell-cell and cell-matrix adhesion by downregulation of $\mathrm{E}$-cadherin and disruption of E-cadherin/ $\beta$-catenin complexes, suggesting an interplay of these cellular proteins in the development of epithelial malignancy $[18,35]$. We have earlier shown that ezrin regulates the composition of cellular junctions containing cadherins and catenins [14]. In HeLa cervical carcinoma cells containing HPV 18 we have shown the displacement of epithelial E-cadherin by mesenchymal N-cadherin [14], which is known to take place in epithelial-mesenchymal transition (EMT) and cancer [36]. Inriguingly, in our present study we found strong apical expression of ezrin in endocervical glands, whereas moderate basolateral but no apical staining was shown for E-cadherin and $\beta$-catenin, suggesting different mechanisms of the formation and maintenance of adherens junctions in columnar and squamous epithelia.

Although testing for high-risk HPV has proved useful in the triage of borderline cytology cases [37], additional markers with prognostic value would contribute to better patient management. We report here that altered ezrin expression is associated with HPV-associated dysplasia in cervical epithelium. Future studies will establish the impact of this finding in clinical evaluation of patients, and in the improvement of intraobserver variation in histological diagnosis. Whether it is possible to find a prognostic marker to differentiate the progressing lesions from the recurring ones within one histological class is a question remaining to be solved. A histological classification does not necessarily represent a single entity of similar lesions. Different expression patterns of viral proteins, surrogate cellular markers for viral oncogene expression, or expression of other cellular proteins may help in the evaluation of disease progression [38]. Therefore, a combination of viral and cellular markers might be valuable in a situation where prognostic markers for cervical carcinogenesis among histologically similar lesions are desired.

Acknowledgements: Dr Magnus von Knebel Doeberitz (Heidelberg, Germany) is greatly acknowledged for his help in p16 staining. Ms Irina Suomalainen, Ms Susanna Ihalainen and Ms Tuula Halmesvaara are acknowledged for excellent technical assistance. This study was supported by grants from the Finnish Cancer Societies to AV and OC.

\section{References}

[1] MELNIKOW J, NUOVO J, WILLAN AR, CHAN BKS, HOWELL LP. Natural history of cervical squamous intraepithelial lesions: a meta-analysis. Obstet Gynecol 1998; 92: 727-735. http://dx.doi.org/10.1016/S0029-7844(98)00245-2

[2] KAMB A, GRUIS NA, WEAVER-FELDHAUS J, LIU Q, HARSHMAN K, et al. A cell cycle regulator potentially involved in genesis of many tumor types. Science 1994; 264 : 436-440. http://dx.doi.org/10.1126/science.8153634

[3] KLAES R, FRIEDRICH T, SPITKOVSKI D, RIDDER R, RUDY W, et al. Overexpression of p16INK4A as a specific marker for dysplastic and neoplastic epithelial cells of the cervix uteri. Int J Cancer 2001; 92: 276-284. http://dx.doi. org/10.1002/ijc.1174

[4] GOULD KL, BRETSCHER A, ESCH FS, HUNTER T. cDNA cloning and sequencing of the protein-tyrosine kinase substrate, ezrin, reveals homology to band 4.1. EMBO J 1989; 8: 4133-4142.

[5] TURUNEN O, WINQVIST R, PAKKANEN R, GRZESCHIK $\mathrm{KH}$, WAHLSTROM T, et al. Cytovillin, a microvillar Mr 75, 000 protein. J Biol Chem 1989; 264: 16727-16732.

[6] VAHERI A, CARPEN O, HEISKA L, HELANDER TS, JAASKELAINEN J, et al. The ezrin protein family: membranecytoskeleton interactions and disease associations. Curr Opin Cell Biol 1997; 9: 659-666. http://dx.doi.org/10.1016/S09550674(97)80119-6

[7] KAUL SC, MITSUI Y, KOMATSU Y, REDDEL RR, WADHWA R. A highly expressed $81 \mathrm{kDa}$ protein in immortalized mouse fibroblast: its proliferative function and identity with ezrin. Oncogene 1996; 13: 1231-1237.

[8] AKISAWA N, NISHIMORI I, IWAMURA T, ONISHI S, HOLLINGSWORTH MA. High levels of ezrin expressed by human pancreatic adenocarcinoma cell lines with high metastatic potential. Biochem Biophys Res Comm 1999; 258: 395-400. http://dx.doi.org/10.1006/bbrc.1999.0653

[9] KHANNA C, KHAN J, NGUYEN P, PREHN J, CAYLOR J, et al. Metastasis-associated differences in gene expression in a murine model of osteosarcoma. Cancer Res 2001; 61: 3750-3759.

[10] SHEN ZY, XU LY, CHEN MH, LI EM, LI JT, et al. Upregulated expression of ezrin and invasive phenotype in malignantly transformed esophageal epithelial cells. World J Gastroenterol 2003; 9: 1182-1186.

[11] KHANNA C, WAN X, BOSE S, CASSADAY R, OLOMU O, et al. The membrane-cytoskeleton linker ezrin is necessary for osteosarcoma metastasis. Nature Med 2004; 10: 182-186. http://dx.doi.org/10.1038/nm982

[12] YU Y, KHAN J, KHANNA C, HELMAN L, MELTZER PS, et al. Expression profiling identifies the cytoskeletal organizer ezrin and the developmental homeoprotein Six-1 as key metastatic regulators. Nature Med 2004; 10: 175-181. http://dx.doi. org/10.1038/nm966

[13] HEISKA L, MELIKOVA M, ZHAO F, SAOTOME I, MCCLATCHEY AI, et al. Ezrin is key regulator of Src-induced malignant phenotype in three-dimensional environment. Oncogene 2011; 30: 4953-4962. http://dx.doi.org/10.1038/ onc.2011.207

[14] AUVINEN E, KIVI N, VAHERI A. Regulation of ezrin localization by Rac1 in epithelial cells. Exp Cell Res 2007; 313: 824-833. http://dx.doi.org/10.1016/j.yexcr.2006.12.002 
[15] GRECO D, KIVI N, QIAN K, LEIVONEN SK, AUVINEN P, et al. Human papillomavirus 16 E5 modulates the expression of host microRNAs. PLoS ONE 2011; 6(7): e21646. http://dx.doi. org/10.1371/journal.pone.0021646

[16] YU Y, DAVICIONI E, TRICHE TJ, MERLINO G. The homeoprotein Six1 transcriptionally activates multiple protumorigenic genes but requires ezrin to promote metastasis. Cancer Res 2006; 66: 1982-1999. http://dx.doi.org/10.1158/ 0008-5472.CAN-05-2360

[17] WAN F, MIAO X, QURAISHI I, KENNEDY V, CREEK KE, et al. Gene expression changes during HPV-mediated carcinogenesis: a comparison between an in vitro cell model and cervical cancer. Int J Cancer 2008; 123: 32-40. http://dx.doi. org/10.1002/ijc.23463

[18] HIROHASHI S, KANAI Y. Cell adhesion system and human cancer morphogenesis. Cancer Sci 2003; 94: 575-581. http:// dx.doi.org/10.1111/j.1349-7006.2003.tb01485.x

[19] CARICO E, ATLANTE M, BUCCI B, NOFRONI I, VECCHIONE A. E-cadherin and $\alpha$-catenin expression during tumor progression of cervical carcinoma. Gynecol Oncol 2001; 80: 156-161. http://dx.doi.org/10.1006/gyno.2000.6035

[20] WILDING J, VOUSDEN KH, SOUTTER WP, MCCREA $\mathrm{PD}, \mathrm{DEL}$ BUONO R, et al. E-cadherin transfection downregulates the epidermal growth factor receptor and reverses the invasive phenotype of human papilloma virus-transfected keratinocytes. Cancer Res 1996; 56: 5285-5292.

[21] BOHLING T, TURUNEN O, JAASKELAINEN J, CARPEN O, SAINIO M, et al. Ezrin expression in stromal cells of capillary hemangioblastoma - an immunohistochemical survey of brain tumors. Am J Pathol 1996; 148: 367-373.

[22] LUGINI L, LOZUPONE F, MATARRESE P, FUNARO C, LUCIANI F, et al. Potent phagocytic activity discriminates metastatic and primary human malignant melanomas: a key role of ezrin. Lab Invest 2003; 83: 1555-1567. http://dx.doi. org/10.1097/01.LAB.0000098425.03006.42

[23] LEONARD P, SHARP T, HENDERSON S, HEWITT D, PRINGLE J, et al. Gene expression array profile of human osteosarcoma. Br J Cancer 2003; 89: 2284-2288. http://dx.doi. org/10.1038/sj.bjc.6601389

[24] MAKITIE T, CARPEN O, VAHERI A, KIVELA T. Ezrin as a prognostic factor and its relationship to tumor characteristics in uveal malignant melanoma. Invest Ophth Vis Sci 2001; 42: 2442-2449.

[25] ILMONEN S, VAHERI A, ASKO-SELJAVAARA S, CARPEN O. Ezrin in primary cutaneous melanoma. Mod Pathol 2005; 18: 503-510. http://dx.doi.org/10.1038/modpathol.3800300

[26] CHEN Z, FADIEL A, FENG Y, OHTANI K, RUTHERFORD $\mathrm{T}$, et al. Ovarian epithelial carcinoma tyrosine phosphorylation, cell proliferation, and ezrin translocation are stimulated by interleukin 1 and epidermal growth factor. Cancer 2001; 92: 3068-3075. http://dx.doi.org/10.1002/1097-0142(200112 15) $92: 12<3068::$ AID-CNCR10149>3.0.CO; 2-5

[27] NESTL A, VON STEIN OD, ZATLOUKAL K, THIES W-G, HERRLICH P, et al. Gene expression patterns associated with the metastatic phenotype in rodent and human tumors. Cancer Res 2001; 61: 1569-1577.

[28] CHIANG Y, CHOU CY, HSU KF, HUANG YF, SHEN MR. EGF upregulates $\mathrm{Na}+\mathrm{H}+$ exchanger NHE1 by post-translational regulation that is important for cervical cancer cell invasiveness. J Cell Physiol 2008; 214: 810-819. http://dx.doi. org/10.1002/jcp. 21277

[29] RODRIGUEZ-SASTRE MA, GONZALEZ-MAYA L, DELGADO R, LIZANO M, TSUBAKI G, et al. Abnormal distribution of E-cadherin and $\beta$-catenin in different histologic types of cancer of the uterine cervix. Gynecol Oncol 2005; 97: 330-336. http://dx.doi.org/10.1016/j.ygyno.2004.12.062

[30] KAPLANIS K, KIZIRIDOU A, LIBERIS V, DESTOUNI C, GALAZIOS G. E-cadherin expression during progression of squamous intraepithelial lesions in the uterine cervix. Eur J Gynaecol Oncol 2005; 26: 608-610.

[31] VAN DE PUTTE G, KRISTENSEN GB, BAEKELANDT M, LIE AK, HOLM R. E-cadherin and catenins in early squamous cervical carcinoma. Gynecol Oncol 2004; 94: 521-527. http://dx.doi.org/10.1016/j.ygyno.2004.05.046

[32] DE BOER CJ, VAN DORST E, VAN KRIEKEN H, JANSENVAN RHIJN CM, WARNAAR SO, et al. Changing roles of cadherins and catenins during progression of squamous intraepithelial lesions in the uterine cervix. Am J Pathol 1999; 155: 505-515. http://dx.doi.org/10.1016/S00029440(10)65146-2

[33] FALEIRO-RODRIGUES C, LOPES C. E-cadherin, CD44 and CD44v6 in squamous intraepithelial lesions and invasive carcinomas of the uterine cervix: an immunohistochemical study. Pathobiol 2004; 71: 329-336. http://dx.doi.org/10.1159/ $\underline{000081729}$

[34] MATTHEWS K, LEONG CM, BAXTER L, INGLIS E, YUN $\mathrm{K}$, et al. Depletion of Langerhans cells in human papillomavirus type 16-infected skin is associated with E6-mediated down regulation of E-cadherin. J Virol 2003; 77: 8378-8385. http://dx.doi.org/10.1128/JVI.77.15.8378-8385.2003

[35] HISCOX S, JIANG WG. Ezrin regulates cell-cell and cellmatrix adhesion, a possible role with E-cadherin/ $\beta$-catenin. J Cell Sci 1999; 112: 3081-3090.

[36] MANI SA, GUO W, LIAO MJ, EATON EN, AYYANAN A, et al. The epithelial-mesenchymal transition generates cells with properties of stem cells. Cell 2008; 133: 704-715. http://dx.doi. org/10.1016/j.cell.2008.03.027

[37] CUZICK J, SZAREWSKI A, CUBIE H, HULMAN G, KITCHENER H, et al. Management of women who test positive for high-risk types of human papillomavirus: the HART study. Lancet 2003; 362: 1871-1876. http://dx.doi.org/10.1016/ $\underline{\text { S0140-6736(03)14955-0 }}$

[38] MIDDLETON K, PEH W, SOUTHERN S, GRIFFIN H, SOTLAR K, et al. Organization of human papillomavirus productive cycle during neoplastic progression provides a basis for selection of diagnostic markers. J Virol 2003; 77: 10186-10201. http://dx.doi.org/10.1128/JVI.77.19.10186$\underline{10201.2003}$ 